\title{
Learning Objects: Adaptive Retrieval through Learning Styles
}

\author{
Pollyana Notargiacomo Mustaro and Ismar Frango Silveira \\ Mackenzie Presbyterian University, São Paulo, Brazil
}

\author{
polly@mackenzie.br ismar@mackenzie.br
}

\begin{abstract}
Nowadays, the amount of information grows in an exponential way, mainly because of technological advances in media. This scenario claims for the development of different skills in order to increase learning abilities, making them personal and customizable. Such factor is significant in a changing society, which implies in a range of mechanisms which would allow to identify, in a non-intrusive way, which learning style some specific student would prefer to perform in order to build knowledge from some learning object under a learning context. This requires defining some strategies in order to recognize adult learner's learning styles for some specific learning context.

This work is based on theoretical references of Felder, Kolb and Gardner, proposing the implementation of a metadata annotation to identificate prime learning styles that are present in specific learning objects. This classification constitutes a starting point to recover learning objects from a repository according to apprentice's profile and experiences. As a result, the effectiveness of the use of learning objects will be improved.
\end{abstract}

Keywords: learning styles, learning objects, repositories, Learning Management Systems (LMS), adaptative systems

\section{Introduction}

Contemporary society is strongly influenced by all technological advances of communication and information systems, from telephony and television through to the Internet. In this sense, 21 st century brings us a wide availability of ICTs (Information and Communication Technologies), which is providing the possibility of a lifelong learning to a changing society, each time more based on a knowledge-based economy.

Design of hypermedia applications for computer-mediated teaching-learning process has been a point of interest for many researchers even before the recent expansion of ICTs usage on this context. Together with this entirely new scenario, theoretical foundations have been built in order to try to categorize the incredibly wide range of ways people, often unconsciously, absorb pieces of

Material published as part of this journal, either on-line or in print, is copyrighted by the Informing Science Institute. Permission to make digital or paper copy of part or all of these works for personal or classroom use is granted without fee provided that the copies are not made or distributed for profit or commercial advantage AND that copies 1) bear this notice in full and 2) give the full citation on the first page. It is permissible to abstract these works so long as credit is given. To copy in all other cases or to republish or to post on a server or to redistribute to lists requires specific permission and payment of a fee. Contact Publisher@InformingScience.org to request redistribution permission. information and build knowledge through them. Therefore, according to cognitive psychology, learning styles could be briefly defined as personal manners to perceive and process information, and how they interact and respond to educational stimuli (Alonso, 1993).

To identify students' learning styles, analytical diagnosis are often performed based on theoretical models that empha- 
size the following kinds of preferences (Curry, 1987):

$\Rightarrow \quad$ instructional/contextual preferences
$\Rightarrow$ information process preferences
$\Rightarrow$ preferences of social interaction
$\Rightarrow$ personality-related preferences

This classificatory schema collaborates in learning processes since they provide information that allows the understanding of the fact that students have distinct ways of learning, but none of them is better or worse than the other. They are simply different.

David Kolb, known as a precursor of the research in this specific area, created in 1983 a theory that classified Learning Styles according to four well-distinct categories, depicted in Table 1 (Kolb \& Whishaw, 2001):

Table 1: Learning Styles, according to Kolb (2001)

\begin{tabular}{|c|c|c|}
\hline & Concrete & Abstract \\
\hline Reflective & $\begin{array}{l}\text { Students classified under this style are } \\
\text { characterized by questioning - which } \\
\text { means, by the predominance of "why?"- } \\
\text { like questions - and by the search for } \\
\text { knowledge through the relationship he/she } \\
\text { establishes among pedagogical content, } \\
\text { his/her previous experiences, interests, } \\
\text { motivation and personal plans for future. }\end{array}$ & $\begin{array}{l}\text { This style deals with students whose learn- } \\
\text { ing is guided mainly by organization and } \\
\text { logic - which means, by the search for the } \\
\text { answer to the question "what?" - and by } \\
\text { reflection. }\end{array}$ \\
\hline Active & $\begin{array}{l}\text { This style is typified by the effective ap- } \\
\text { plication of learning content to new situa- } \\
\text { tions, often using them to solve real-life } \\
\text { problems. People with this style being pre- } \\
\text { dominant are usually more creative and are } \\
\text { always searching new links, alternative } \\
\text { scenarios and ideas through questioning } \\
\text { "what if...?". }\end{array}$ & $\begin{array}{l}\text { It is distinguished by actions taken from } \\
\text { structured tasks. In this way, learning is } \\
\text { performed by empirics, which is only pos- } \\
\text { sible in learning contents where there is no } \\
\text { punishment for errors committed during } \\
\text { learning process, since they are part of it. }\end{array}$ \\
\hline
\end{tabular}

On the other hand, Felder's work (Felder, 1988; Felder \& Soloman, 1993) proposes a variation to Kolb's position, establishing relationships among styles and the ways information is dealt by:

$\rightarrow$ Active / Reflective (Related to Information Processing) - Active people consider having understood a piece of information only if they discussed it, applied it or tried to explain it to other people. Reflexive people, on the other hand, prefer reflecting about the issue before assuming any practical posture.

$\rightarrow$ Sensorial / Intuitive (Associated with Information Perception) - Sensorial people are meant to learn from tasks related to problems and facts that could be solved by well-behaved methods, with no surprises or unexpected effects. Besides, this style usually refers to students that are fond of details and very good memorizers of facts and practical applications. Conversely, intuitive students are meant to discover alternate possibilities and relationships by themselves, working with abstractions and formula, which allows them to understand new concepts and to quickly and innovatively perform new tasks. 
> Visual / Verbal (Referring to Information Retaining) - Visual-driven people find no difficulties in interpreting, for an example, pictures, diagrams, timelines or movies. Distinctly, verbal students' personal learning processes are driven by written or spoken explanation - being the most widely used learning style in formal education.

$\rightarrow$ Sequential / Global (Connected to Information Organization) - Sequential people structure their learning process by logically, successively chained steps, each one of them related to the search for solutions. On the other hand, global students learning processes are distinguished by random jumps: they often are able to solve a complex problem, although they do not know how they arrived at the solution.

Figure 1 shows a Picture organizing learning styles according to Felder's classification.

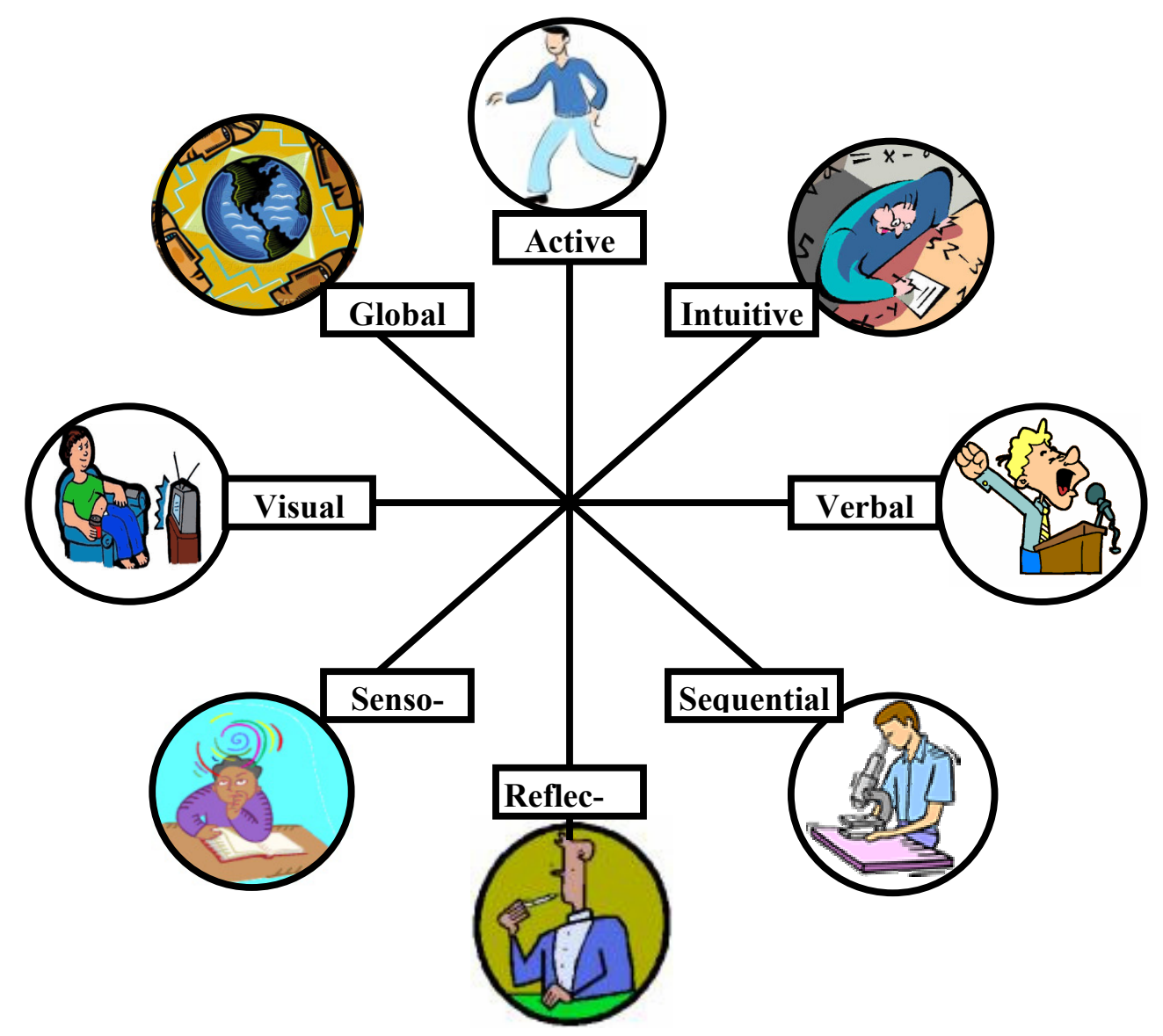

Figure 1 - Felder's learning styles

Howard Gardner's multiple intelligences $(1983,1993,1999)$ complement these categories, by agreeing that teaching-learning processes should focus on the particular "intelligences" of each person. His definition for intelligence is 'a bio-psychological potential to process information that may be activated in a cultural scenario to solve problems or to create products that are valued in a culture" (1999, p. 47). Thus, the seven abilities proposed by Gardner are:

> Linguistic intelligence refers to people's capability of learning best through language - including speaking, writing, reading, and listening. It involves sensitivity 
to spoken and written language, the ability to learn languages, and the capacity to use language to accomplish certain goals. This intelligence includes the ability to effectively use language to express oneself rhetorically or poetically; and language as a means to remember information. They are able to verbally or in writing explain, convince, and express themselves.

$\rightarrow$ Logical-mathematical intelligence is related to people who learn better through numbers, reasoning, and problem solving. It consists on the capacity to analyze problems logically, carry out mathematical operations, and investigate issues scientifically. In Howard Gardner's words, it entails the ability to detect patterns, reason deductively and think logically.

$\rightarrow$ Musical-rhythmic intelligence involves skill in the performance, composition, and appreciation of musical patterns. Learning processes are performed through sounds - including listening and making sounds such as songs, rhythms, patterns, and other types of auditory expression.

$\rightarrow$ Bodily-kinesthetic intelligence entails the potential of using one's whole body or parts of the body to solve problems. It is the ability to use mental abilities to coordinate bodily movements. Under this style are people who learn best through physical activity such as dance, hands-on tasks, constructing models, and any kind of movement. They are able to manipulate and control objects, as well as express their ideas through movement.

$\rightarrow$ Visual-Spatial intelligence refers to the ability people have to learn visually, organizing their thinking spatially.

$\rightarrow$ Interpersonal intelligence is concerned with the capacity to understand the intentions, motivations and desires of other people. Learning is usually achieved through cooperative work or social activities.

- Intrapersonal intelligence entails the capacity to understand oneself, to appreciate one's feelings, fears and motivations. This style depicts concentrated, mindful students, encouraging metacognitive practices such as getting in touch with their own feelings and self motivation.

In order to construct a scenario that would be able to take advantage of these theoretical approaches and integrate them into a LMS (Learning Management System) for adult learners, instructional design elements will be used. Instructional design could be defined as a systematic process based on educational theories, development of educational strategies and specifications to promote high-quality experiences of learning. Thus, instructional planning covers from analysis of needs and learning goals to implementation of the proposal, its evaluation and contents maintenance. The establishment of such a planning is based on the following phases (Gagné, Brigss, \& Wager, 1992):

$>$ Definition of learning goals.

$\rightarrow$ Analysis of learning phases (task analysis) and identification of needed skills and abilities to reach such goals.

$\rightarrow$ Specification of target students.

$\rightarrow$ Description of educational goals.

$\rightarrow$ Selection of methodological strategies.

$\rightarrow$ Collection, organization, adaptation and structuring of the content to be used.

$\rightarrow$ Planning and implementation of formative evaluation, performed along with learning process.

$\rightarrow$ Planning and implementation of conclusive evaluation, carried out at the end of each learning phase. 
Revisions and evaluations are transversal aspects of all phases of instructional design. The present proposal allows some corrections and modifications during learning object's elaboration phases. In a special case, the development of learning objects that takes into account the difference between student's learning styles makes necessary the decomposition of task analysis in subtasks (Figure 2). This architecture begins with the selection of theoretical approach for building the framework. The second stage consists on establishing a relational structure that extends the granularity of the learning object, according to the learning style being considered. After this, there are further steps related to the development of learning styles and their placement into the repository. At the end of the process, it would be possible to determine which objects inside a repository would be more accurately adequate to a certain educational context.

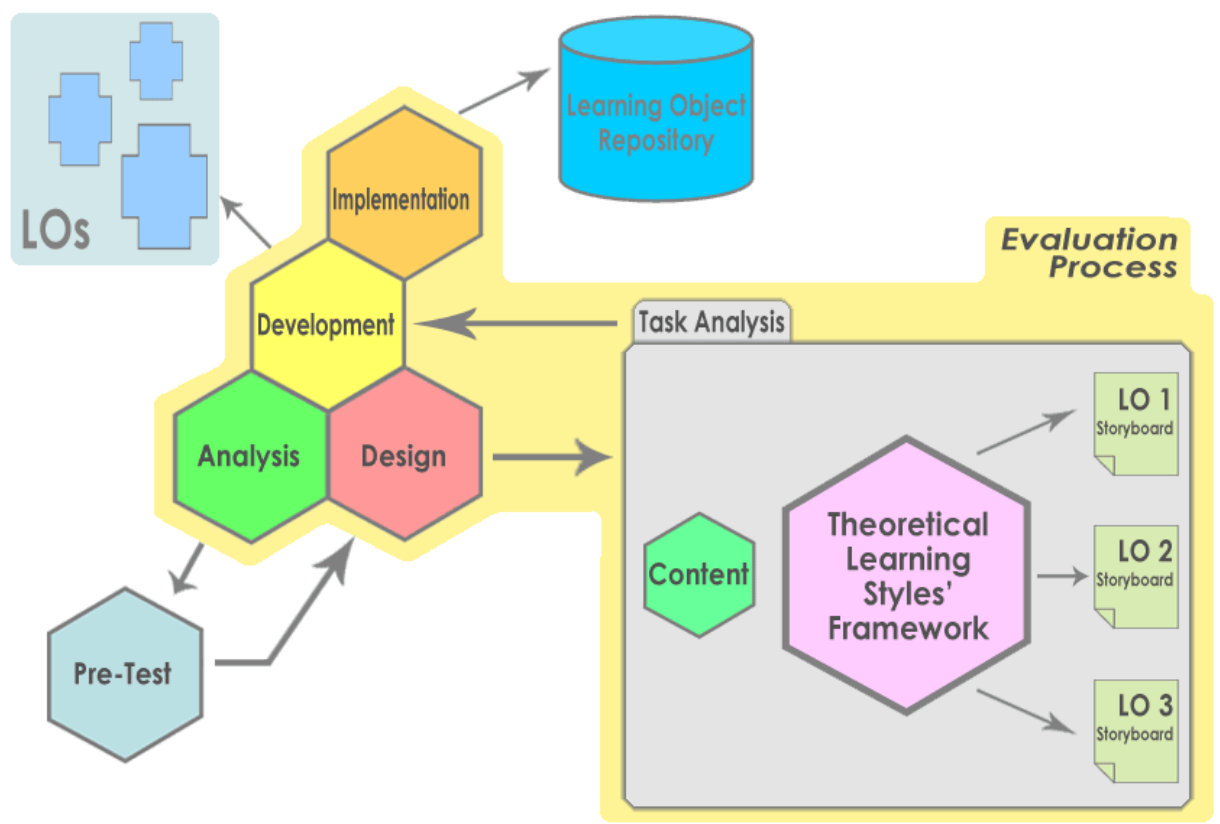

Figure 2 - Instructional Design Process

In order to develop the sequence of phases previously cited, it is also necessary to pay attention to Gagné's (1974) nine instructional events related to cognitive learning processes, as follows:

$\rightarrow$ Attention - related to motivation for learning, i.e., how to increase the reception of information.

$\rightarrow$ Expectative - based in goals and requirements presentation.

$\rightarrow$ Recuperation - covers the exhibition of "mementoes" (stimuli meant to recover previous pieces of learning).

> Selective perception - refers to the presentation of stimuli and information.

$>$ Semantic codification -offers a structure aimed to learning orientation.

$\rightarrow$ Response - its goal is related to practical information retrieval and learning level verification.

$\rightarrow$ Reinforcement - is related to providing feedback.

$\rightarrow$ Performance - recovers and evaluates newly built knowledge.

$\rightarrow$ Generalization - this last phase - also called retention optimizing - has as its basis the ability to apply learning, transferring it to others contexts. 
Figure 3 shows these nine Gagné's instructional events through a spiral-shaped model based in Silveira, Mustaro and Omar (2004).

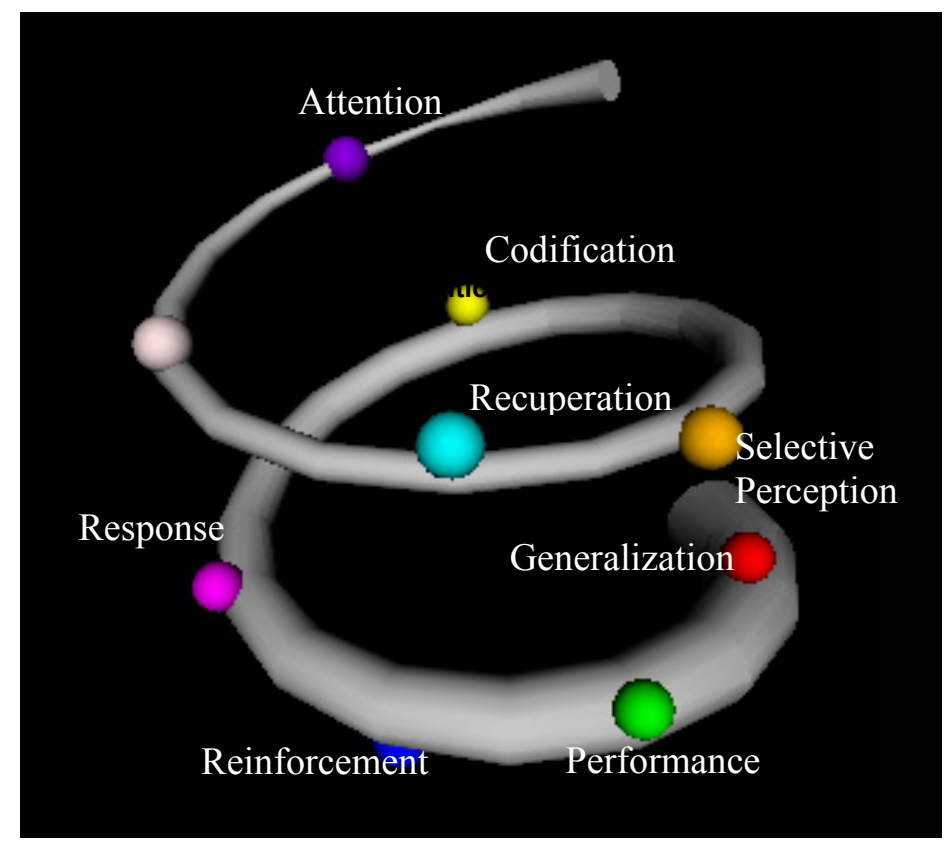

Figure 3 - Spiral-shaped model of Gagné's nine instructional events

This spiral-shaped representation becomes useful when such model is applied as a recurring part of a whole. Thus, this model does not be assumed as a representation of some apprentice's learning conditions: all teaching-learning agents could interfere in instructional events of another agent, thus contributing for a collective, collaborative knowledge building process.

Regarding this, every proposal for instructional design needs to be complemented by an analysis and reflection on how ICTs could collaborate in the process. Therefore, the use of digital media and technologies in projects involving learning styles requires the accomplishment of an analysis of adequacy. Thus, it is needed to know all pedagogical specificities, potentialities and limitations of available tools. The relationship between education and technology implies that the usage of a 'technology' (in the sense of a technical device) in a teaching-learning context, must be accompanied by a reflection on 'technology' (in the sense of the knowledge inserted in the device and its context of production and use).

Facing this, some universities and research groups spread around the world are currently working to make educational resources available in repositories, which could support information storage and their labeling through some standardized metadata (Namuth, Fritz, King, \& Boren, 2005). These elements usually are called learning objects, whose brief description considers them components able to communicate a unique idea, or a series of concepts that represent a unit of learning with complete sense, ready to be used, reused or referenced during the whole computermediated educational process (Wiley, 2000). The next section will describe how learning styles could be combined with learning objects in order to make them adaptive. 


\section{Adaptive Learning Objects}

The definition used for learning objects considers them as any digital entity which can be used, reused or referenced during a technology-mediated learning process (Wiley, 2000). Nowadays, this concept has became essential to the development of pedagogical content to be used in large scale educational projects to which are engaged a wide number of educational agents - students, teachers and faculty staff. Guaranteeing reusability of pedagogical content allows its use in different contexts. Therefore, a repository of learning objects that has a well-defined metadata structure can be used to customize learning processes.

Adaptive learning objects have been discussed from many different viewpoints, regarding learner's adaptation through interoperability issues (Arapi, Moumoutzis, \& Christodoulakis, 2003; Brusilovsky, 2004; Friesen, 2005). Recent researches on Learning Objects are contributing for the search of patterns for instructional content development, in order to make them adaptive, generic, portable and scalable enough to improve their potential for reusability (Bodendorf, Schertler, \& Cohen, 2005). Besides, a wide range of virtual learning environments has been proposed to support these learning objects, with their properties and characteristics. Nonetheless, the great challenge still remains on how adaptive a learning object could be.

Figure 4, adapted from Silveira et al. (2004), presents an architectural proposal for learning objects, supporting interoperability and adaptation.

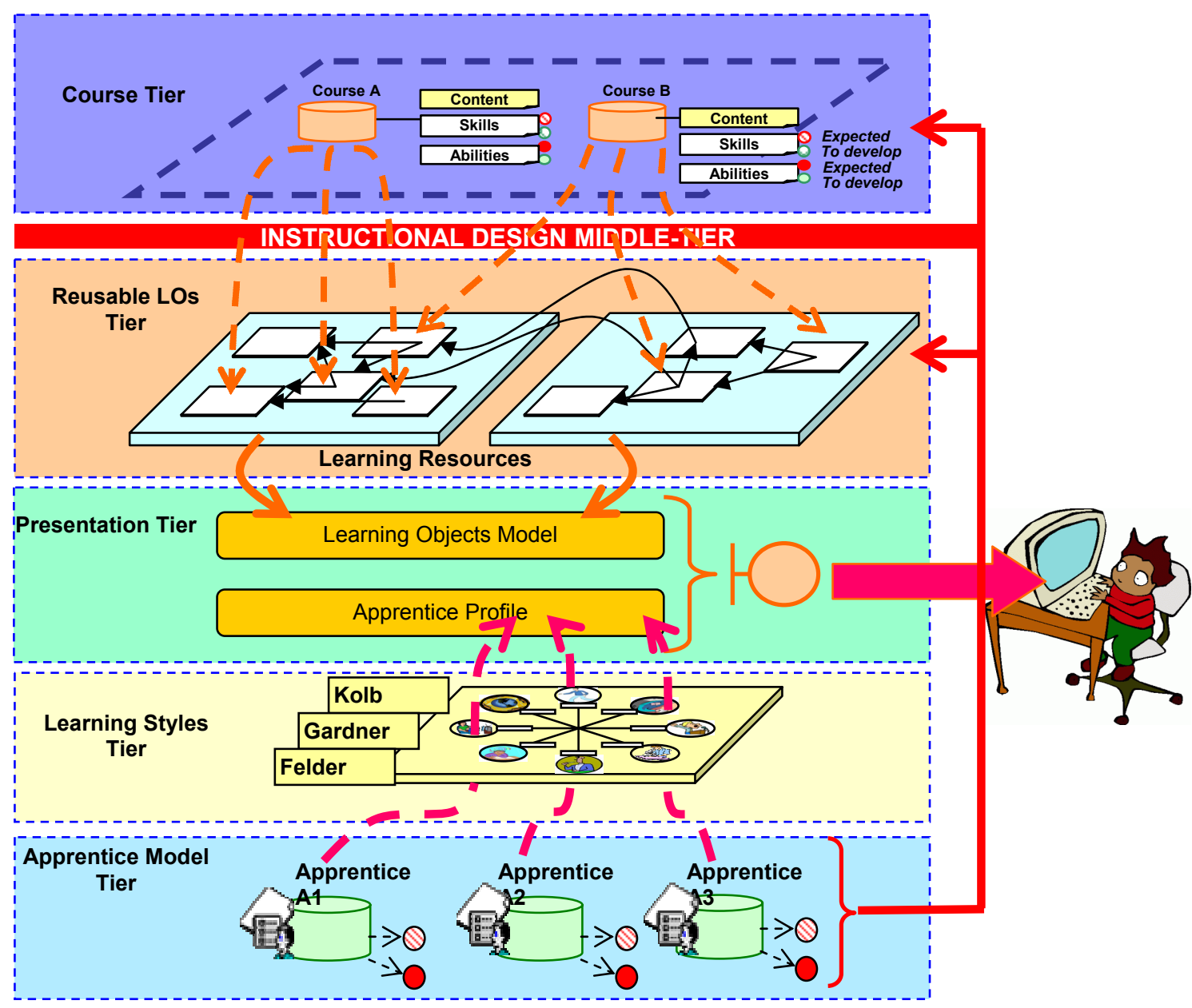

Figure 4 - Six-tiered architecture for adaptive learning objects 
Besides providing interoperability through metadata, by customizing repositories contents according to each particular learning experience, the architecture for repositories proposed in Figure 4 would allow learning objects to be retrieved in an adaptive way, according to learners' historical background, to learning styles, and to learning objectives. Thus, knowledge building process is improved, since relevance and significance of learning objects are strengthened inside a wider learning context. The layers of this architecture are described in the following sections.

\section{Course Tier}

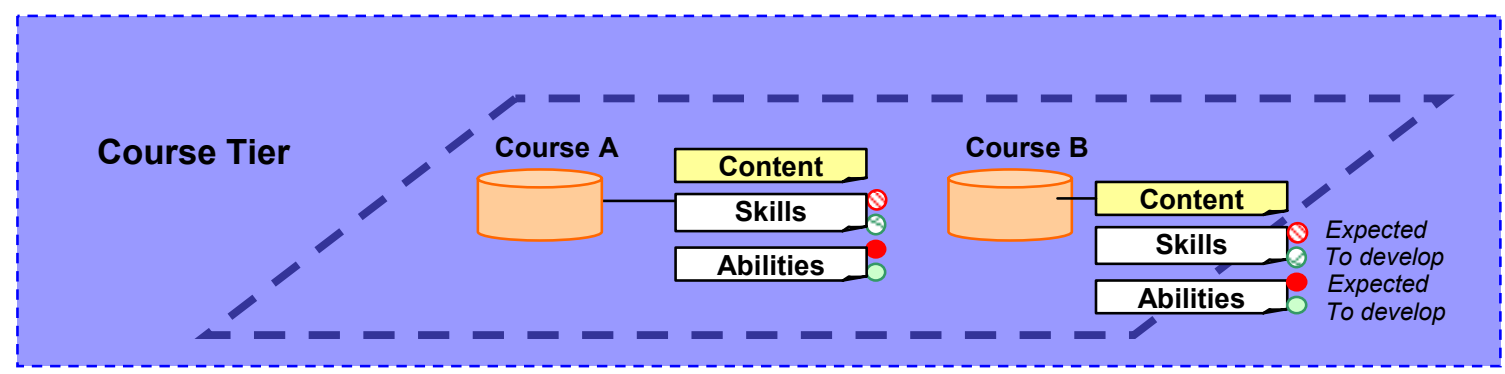

Figure 4.a - Course Tier

The courses, which could be considered as learning object resources, or even course gained objects are found within this tier. Courses are meant to be built as aggregations of finer-grained learning objects and/or resources. These learning objects are usually selected from previously elected subsets built under some instructional design strategy. This strategy is represented in Figure 4 as a middle-tier, which usually defines learning objects selection and sequencing, according to learning objectives. However, since learning styles-based adaptation is to be considered, both steps must be done in a wider or loosely-coupled way, letting to adaptive heuristics decide which objects are more adequate to be shown to a certain student in some learning context.

It must be noted that learning objectives must be established in this tier, in order that each course has the definition of expected skills and abilities, as well as these ones meant to be developed. Again, since different students present distinct learning needs, this classification is not expected to have a static application, but a dynamic one, according to learning styles and profiles that are to be gathered.

\section{Reusable Learning Objects Tier}

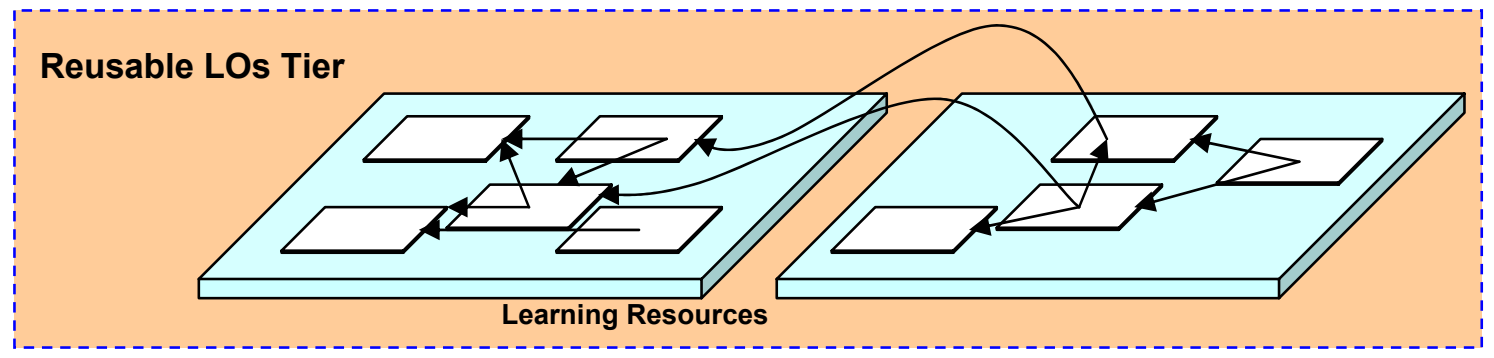

Figure 4.b - Reusable LOs Tier

In this tier dwell all learning objects - or references to them. Playing the role of components that are going to be part of bigger, coarse-grained learning resources, learning objects are usually organized in repositories - that could be an implementation of this tier - and then retrieved from them. Learning objects could also be retrieved form other interoperable repositories. They would have not only to allow storage and retrieval of data, but also its sharing and reuse. Nowadays, a significant amount of learning objects repositories interoperate on the Internet, providing a very large range of elements to be retrieved, exposed and shared. Interoperability among learning ob- 
jects repositories often relies on three techniques: federated searches, LO harvesting through metadata, and finally LO gathering (Arms et al., 2002; Goldrei, Kay, \& Kummerfeld, 2005; Massart \& Dung, 2004). This becomes possible when repositories follow some standards to describe their learning objects, like LOM or SCORM (ADL, 2005; IEEE, 2005). These standards, usually based on categorization and classification of learning objects, are extremely important in learning objects' discovery and recovery processes. For instance, SCORM (Sharable Content Object Reference Model) (ADL, 2005) is a collection of XML-based specifications that allows to catalogue, launch and track educational contents, thus enabling their reusability, accessibility and interoperability.

Development of learning objects repositories follows, in many senses, the same path all digital repositories must go through: data must be modeled in order to fit repositories structural requirements, relationships among such data shall be established and indexing/referencing strategies ought to be implemented. On the other hand, it must be considered that learning objects have some inherent characteristics that could not be bypassed, whose representations into repositories are equally needed and hard to be implemented. Most of these characteristics are related to the learning objectives of each learning object, and the hardness to represent them relies on the subjectivity of these objectives, since they could be related to so many different learning aspects which could vary from students' learning styles through pedagogical strategies

\section{Apprentice Model Tier}

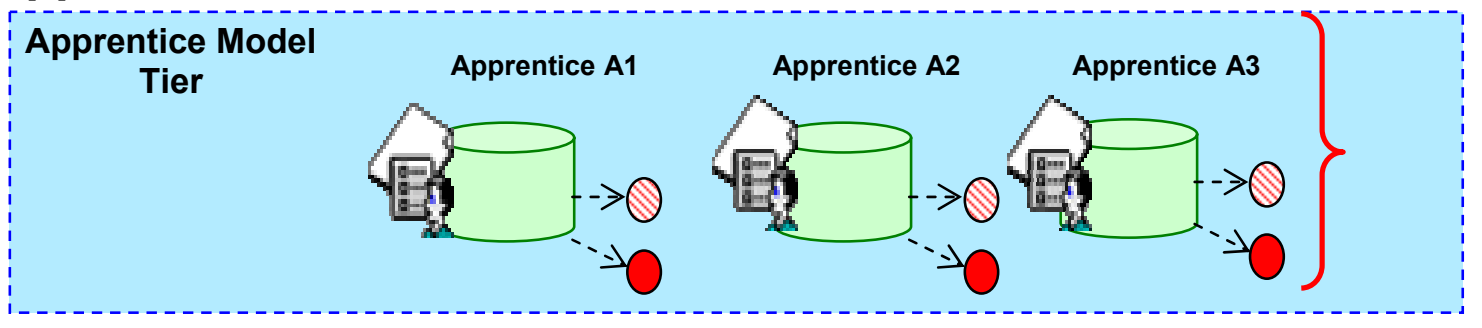

Figure 4.c-Apprentice Model Tier

This tier is responsible for keeping track of students' historical information, being useful to retrieve information about what learning objects inside a learning history have already been presented and which were the learning gains measured from evaluation process. In each learner's individual profile repository, information about individual learning expectances and goals could also be stored. All these pieces of information are extremely important to provide adaptation in a historical, prerequisite-based way.

Nonetheless, there are several levels of adaptation that can be reached, and these levels can be established regarding to a wide range of different aspects on teaching-learning processes, varying from the need of keeping track of students' evolution on building a specified piece of desired knowledge, until their learning styles, which could be inferred from historical data as well as heuristic-based processes through indirect multimedia instruments.

\section{Learning Styles Tier}

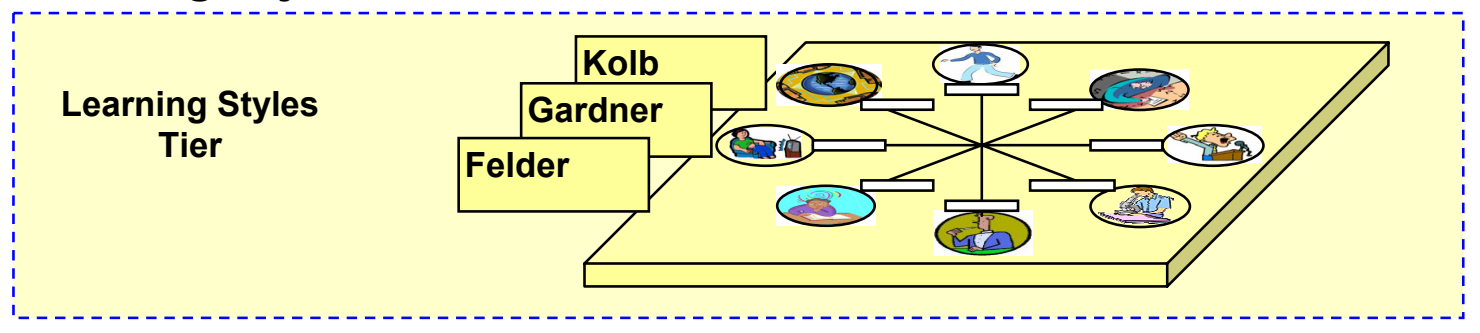


Figure 4.d - Learning Styles Tier

Learning styles are here considered a multi-dimensional measure that are not only individualdependant, but are also influenced by a range of factors so diverse as environment, inter-relational issues and psychological aspects related to how a student deals with the certain sort of knowledge to be constructed, or skill to be developed. As previously stated this work draws on research from Kolb, Felder and Gardner related to the classification of learning styles.

Figure 3.d metaphors learning styles as filters. Students' profiles are meant to pass through in order to create a learning style-dependant apprentice profile. It must be noted that styles are not dependant only of students' historical profile, but also of knowledge's nature. More than this, student's learning styles are not meant to be static or immutable, which makes them harder to be computationally represented.

\section{Presentation Tier}

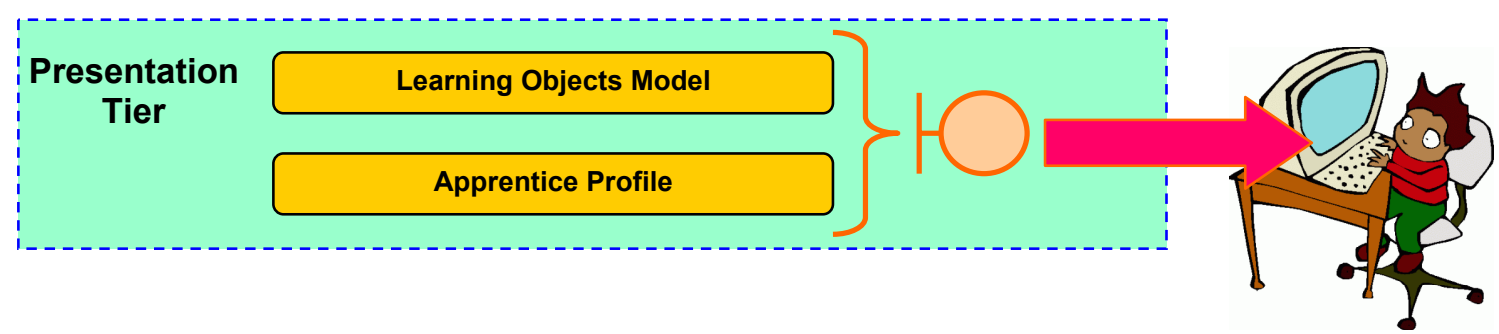

Figure 4.e - Presentation Tier

The presentation layer is responsible for the dynamic generation of a suitable visualization of learning objects according to a learner's profile, taking in account his/her inferred learning styles for a certain learning context. This is the last tier to be executed, since it depends on all others to perform their tasks.

Presentation tier is, in fact, composed of two parts: a "Learning Objects Model", which describes all learning objects that are to be used in the learning context, according to a basic sequencing defined by the Instructional Design middle-tier for some course; and an "Apprentice Profile", formed by learner's historical profile and by learning styles that are detected according to the learning context in question.

\section{Conclusions}

The need for providing personalized learning experiences results in new educational proposals to be presented. These proposals must take into account an information-dependant, fully-networked, rapid and dynamic society whose components are inherently and each time more heterogeneous people with different expectancies, anxieties and needs. In order to accurately provide an adequate fulfillment to individual learning requirements, such educational proposals must keep track of more than historical aspects of one's evolution in his/her learning process during lifetime: different learning styles, naturally developed by each student, are to be considered, properly modeled and effectively used for learning purposes.

This paper presented architecture for organizing learning objects in a macrostructure - which could be a repository or even a whole LMS - in order to support more than storage and retrieval of objects, but also learners' profiles, learning objectives, structure of courses and so on. Future work is to be done in order to model and build non-invasive, indirect, heuristic-based ways to detect learning styles automatically without having to make them non-transparent to the student. By providing proper multimedia-based instruments to help in the inferring process of one's learning styles according to some learning context, learning styles could be fully implemented in the 
proposed architecture, making personalized adaptation of learning objects a reality in the learning process.

\section{References}

ADL. (2005). Advanced distributed learning. Retrieved November 28, 2005, from http://www.adlnet.org

Alonso, C. M. (1993). Educational technology and learning styles. Rethinking the Roles of Technology in Education. The Tenth International Conference on Technology and Education, p. 1277-1279. USA, Massachusetts Institute of Technology and The University of Texas at Austin.

Arapi, P., Moumoutzis, N. \& Christodoulakis, S. (2003). Supporting interoperability in an existing elearning platform using SCORM. Proceedings of 3rd IEEE Intl. Conf. on Advanced Learning Technologies. Athens, Greece, July.

Arms, W. Y., Hillmann, D., Lagoze, C., Krafft, D., Saylor, J., Terrizzi, C. \& van de Sompel, H. (2002). A spectrum of interoperability: The site for science prototype for the NSDL. D-Lib Magazine, 8, 1, January.

Bodendorf, F., Schertler, M. \& Cohen E. (2005). Producing reusable web-based multimedia presentations. Interdisciplinary Journal of Knowledge and Learning Objects, 1, 127-14. Retrieved January 15, 2006, from http://www.ijklo.org/Volume1/v1p127-142Bodendorf.pdf

Brusilovsky, P. (2004). Adaptive e-learning systems: KnowledgeTree: A distributed architecture for adaptive e-learning. Proceedings of the 13th international World Wide Web conference on Alternate track papers \& posters. New York, May.

Curry, L. (1987). Integrating concepts of cognitive or learning style: A review with attention to psychometric standards. Ottawa, ON: Canadian College of Health Service Executives.

Felder, R. M. (1988). Learning and teaching styles in engineering education. Engineering Education, 78(7), 674-681.

Felder, R. M. \& Soloman, B. A. (1993). Learning styles and strategies. Retrieved December 02, 2005, from http://www.ncsu.edu/felder-public/ILSdir/styles.htm

Friesen, N. (2005). Interoperability and learning objects: An overview of e-learning standardization. Interdisciplinary Journal of Knowledge and Learning Objects, 1, 23-31. Retrieved January 15, 2006, from http://www.ijklo.org/Volume1/v1p023-031Friesen.pdf

Gagné, R. M. (1974). Essentials of learning for instruction. (2nd ed.). Hinsdale, IL: The Dryden Press.

Gagné, R. M., Brigss, L. J. \& Wager, W. (1992). Principles of instructional design. Orlando, FL: Harcourt Brace Jovanovich College Publishers.

Gardner, H. (1983). Frames of mind: The theory of multiple intelligences. New York: Basic Books.

Gardner, H. (1993). Multiple Intelligences: The theory in practice. NY: Basic Books.

Gardner, H. (1999). Intelligence reframed: Multiple intelligences for the 21st century. New York: Basic Books.

Goldrei, S., Kay, J. \& Kummerfeld, B. (2005). Exploiting user models to automate the harvesting of metadata for Learning Objects. Proceedings of 2005 Conf. on Adaptive and intelligent Web-based educational systems (AIWBES'05), Málaga, España.

Kolb, B. \& Wishaw, I. Q. (2005). An introduction to brain and behaviour. (2nd ed.). Worth Publishers.

IEEE LTSC. (2005). Learning object metadata. Retrieved November 20, 2005, from http://ieeeltsc.org/wg12LOM/

Massart, D. \& Dung, L. T. (2004.) Federated search of learning object repositories: The CeLeBraTe approach. Proceedings of International Conference RIFV'04. Hanoi, Vietnam. 
Namuth, D., Fritz, S., King, J. \& Boren, M. (2005). Principles of sustainable learning objects libraries. Interdisciplinary Journal of Knowledge and Learning Objects, 1, 181-196. Retrieved January 15, 2006, from http://www.ijklo.org/Volume1/v1p181-196Namuth.pdf

Silveira, I. F., Mustaro, P. N. \& Omar, N. (2004). Aprendizagem significativa baseada em uma arquitetura multicamadas de objetos de aprendizagem adaptativos. VII Congresso IberoAmericano de Informática Educativa, Monterrey. Anais do RIBIE 2004, v. 1.

Wiley, D. A. (2000) Learning object design and sequencing theory. PhD Thesis. Brigham Young University.

\section{Biographies}

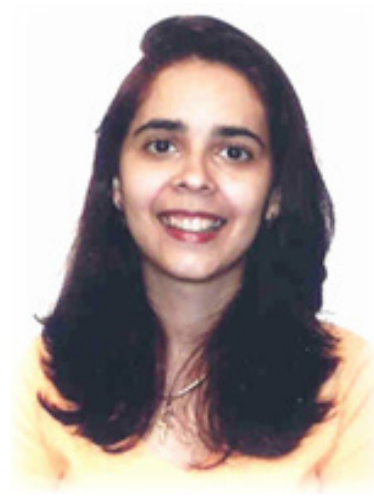

Pollyana Notargiacomo Mustaro obtained her PhD in Education (São Paulo University - USP, 2003), being specialized on Internet hackers' Knowledge Building Process. Nowadays, she is a professor at Mackenzie Presbyterian University. Her research areas include Learning Objects Theory, Learning Styles, Instructional Design and Distance Learning.

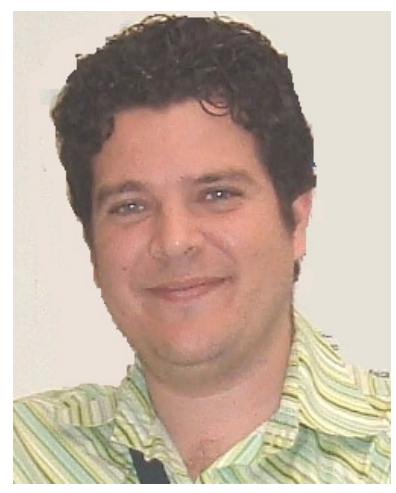

Ismar Frango Silveira defended his $\mathrm{PhD}$ thesis in Distributed Objects applied to Virtual Reality-based Learning Environments in May 2003, at São Paulo University (USP). Currently, he is involved with researches in Adaptive Learning Objects and Collaborative Learning. He presently teaches at Mackenzie Presbyterian University and Cruzeiro do Sul University (UNICSUL), both in São Paulo, Brazil. 